\title{
Liquid/liquid interfacial Suzuki polymerization prepared novel triphenylamine-based conjugated polymer films with excellent electrochromic properties
}

Ling Zhang, Wang Zhan, Yujie Dong, Tao Yang, Cheng Zhang, Mi Ouyang* and Weijun $\mathrm{Li}^{*}$

International Sci. \& Tech. Cooperation Base of Energy Materials and Application, College of Chemical Engineering, Zhejiang University of Technology, Hangzhou 310014, P. R. China

Corresponding Author

*E-mail: ouyang@,zjut.edu.cn Tel: +86-571-88320929

*E-mail: liwj@zjut.edu.cn Tel: +86-571-88320929

The synthesis of monomers 

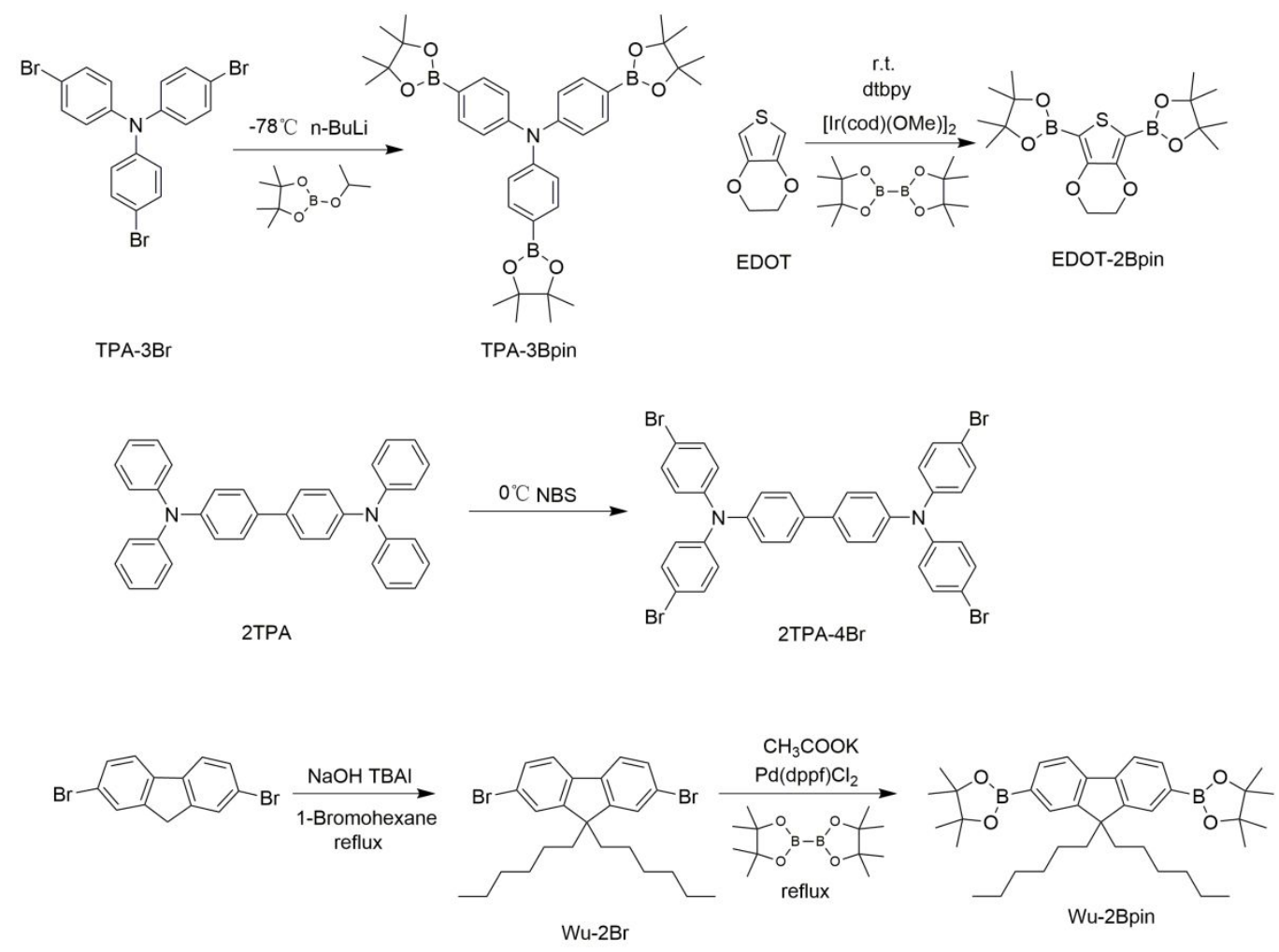

Scheme 1. Synthesis routes of the monomers TPA-3Bpin, EDOT-2Bpin, 2TPA-4Br and $\mathrm{Wu}-2 \mathrm{Bpin}$.

\section{$N^{4}, N^{4}, N^{4^{\prime}}, N^{4^{\prime}}$-tetrakis(4-bromophenyl)-[1,1'-biphenyl]-4,4'-diamine (2TPA-4Br):}

According to the general procedure, into a $100 \mathrm{~mL}$ round-bottom flask were added $N^{4}, N^{4}, N^{4^{\prime}}, N^{4^{\prime}}$-tetraphenyl-[1,1'-biphenyl]-4,4'-diamine (1.466 g, $3 \mathrm{mmol}$ ), NBS $(2.56 \mathrm{~g}, 14.4 \mathrm{mmol})$ and chloroform $(50 \mathrm{~mL})$. The resultant mixture was stirred at $0{ }^{\circ} \mathrm{C}$ and then at room temperature for overnight. The reaction mixture was extracted with dichloromethane and washed with deionized water and brine solution. Then the combined organic layer was dried over $\mathrm{Na}_{2} \mathrm{SO}_{4}$, and concentrated under vacuum. The crude product was purified by silica-gel column using chloroform/hexane (1:3 by volume) as eluent to afford as a grey-white solid (1.93g, yield $80 \%$ ). MALDI-TOF-MS (M) $(\mathrm{m} / \mathrm{z})=803.797[\mathrm{M}+\mathrm{H}]^{+} .{ }^{1} \mathrm{H}$ NMR $\left(600 \mathrm{MHz}, \mathrm{CDCl}_{3}\right) \delta 7.47$ $(\mathrm{d}, J=8.0 \mathrm{~Hz}, 4 \mathrm{H}), 7.39(\mathrm{~d}, J=8.7 \mathrm{~Hz}, 8 \mathrm{H}), 7.11(\mathrm{~d}, J=6.3 \mathrm{~Hz}, 4 \mathrm{H}), 7.00(\mathrm{~d}, J=8.4$ $\mathrm{Hz}, 8 \mathrm{H})$. 


\section{5,7-bis(4,4,5,5-tetramethyl-1,3,2-dioxaborolan-2-yl)-2,3-dihydrothieno[3,4-b][1,4] dioxine (EDOT-2Bpin):}

According to the general procedure, bis(pinacolato)diboron (1.02 g, $4 \mathrm{mmol})$, $[\operatorname{Ir}(\mathrm{cod})(\mathrm{OMe})]_{2}(20 \mathrm{mg}, 0.03 \mathrm{mmol}), 3,4-$ ethylenedioxy-thiophene (EDOT) $(0.284 \mathrm{~g}$, $2 \mathrm{mmol})$ and dtbpy $(8 \mathrm{mg}, 0.030 \mathrm{mmol})$ were added to a round-bottom flask under nitrogen. Then $15 \mathrm{~mL}$ hexane was added into it. The reaction mixture was stirred at room temperature for $15 \mathrm{~h}$. After filtration and washing with hexane, the target compound was obtained as a white crystalline solid (0.63 g, yield 80\%). MALDI-TOF-MS (M) (m/z) = 394.15 [M + H] $]^{+} .{ }^{1} \mathrm{H}$ NMR $\left(600 \mathrm{MHz}, \mathrm{CDCl}_{3}\right) \delta 4.30$ (s, 4H), 1.35 (s, 24H).

\section{Tris(4-(4,4,5,5-tetramethyl-1,3,2-dioxaborolan-2-yl)phenyl)amine (TPA-3Bpin):}

To a cooled solution of tris(4-bromophenyl)-amine $(2.41 \mathrm{~g}, 5 \mathrm{mmol})$ in anhydrous THF $(20 \mathrm{~mL})$ at $-78^{\circ} \mathrm{C}$, a solution of $\mathrm{n}-\mathrm{BuLi}(24 \mathrm{mmol}, 2.4 \mathrm{M})$ in n-hexane was added dropwise under nitrogen. After stirred for $30 \mathrm{~min}$, the reaction mixture was slowly warmed to room temperature by removing the cooling bath. Afterwards, the mixture was cooled to $-78^{\circ} \mathrm{C}$ again and added with 2-isopropoxy-4,4,5,5-tetramethyl-1,3,2-dioxaborolane (4.65 g, $25 \mathrm{mmol}$ ) dropwise and stirred for $1 \mathrm{~h}$. The cooling bath was removed then, and the reaction mixture was naturally warm to room temperature and then stirred overnight. The reaction mixture was extracted with dichloromethane and washed with deionized water and brine solution. Then the combined organic layer was dried over $\mathrm{Na}_{2} \mathrm{SO}_{4}$, and concentrated under vacuum. The obtained crude product was recrystallized from dichloromethane-methanol, obtaining the target product as a white solid (2.27 g, yield 72\%). MALDI-TOF-MS (M) $(\mathrm{m} / \mathrm{z})=623.3[\mathrm{M}+\mathrm{H}]^{+} .{ }^{1} \mathrm{H}$ NMR $\left(600 \mathrm{MHz}, \mathrm{CDCl}_{3}\right) \delta 7.70(\mathrm{~d}, J=8.5 \mathrm{~Hz}, 6 \mathrm{H}), 7.09(\mathrm{~d}, J=8.5 \mathrm{~Hz}, 6 \mathrm{H}), 1.36(\mathrm{~s}$, $36 \mathrm{H})$.

\section{2,7-dibromo-9,9-dihexyl-9H-fluorene (Wu-2Br):}

2,7-dibromo-9H-fluorene (0.42 g, $1.296 \mathrm{mmol}), 50 \%$ aq $\mathrm{NaOH}(10 \mathrm{~mL})$, and tetrabutylammonium iodide $(0.092 \mathrm{~g}, 10 \mathrm{~mol} \%)$ were added to a 
round-bottom flask under nitrogen. 1-bromohexane (1.48 g, $9.072 \mathrm{mmol})$ was added and the mixture with strong stirring under reflux for $8 \mathrm{~h}$. The reaction mixture was cooled to room temperature and extracted with dichloromethane and washed with deionized water and brine solution. Then the combined organic layer was dried over $\mathrm{Na}_{2} \mathrm{SO}_{4}$, and concentrated under vacuum. The crude product was purified by silica-gel column using chloroform/hexane (1:9 by volume) as eluent to afford as a white solid (0.5 g, yield 79\%). ${ }^{1} \mathrm{H}$ NMR (600 MHz, $\left.\mathrm{CDCl}_{3}\right) \delta 7.52(\mathrm{~d}, J=$ $7.9 \mathrm{~Hz}, 2 \mathrm{H}), 7.46(\mathrm{~d}, J=8.0 \mathrm{~Hz}, 4 \mathrm{H}), 1.91(\mathrm{~m}, 4 \mathrm{H}), 1.05(\mathrm{~m}, 12 \mathrm{H}), 0.78(\mathrm{~m}, 6 \mathrm{H}), 0.58$ $(\mathrm{m}, 4 \mathrm{H})$.

2,2'-(9,9-dihexyl-9H-fluorene-2,7-diyl)bis(4,4,5,5-tetramethyl-1,3,2-dioxaborolan e) (Wu-2Bpin):

2,7-dibromo-9,9-hexyl-9H-fluorene (Wu-2Br) (0.3 g, $0.6 \mathrm{mmol})$, potassium acetate $\left(\mathrm{CH}_{3} \mathrm{COOK}\right)(0.176 \mathrm{~g}, 1.8 \mathrm{mmol})$, bis(pinacolato)diboron (0.61 g, $2.4 \mathrm{mmol}), \quad \mathrm{Pd}(\mathrm{dppf}) \mathrm{Cl}_{2}(22 \mathrm{mg}, 0.03 \mathrm{mmol})$ and anhydrous 1,4-dioxane $(20 \mathrm{~mL})$ were added to a round-bottom flask under nitrogen. The mixture was heated to reflux with strong stirring for $24 \mathrm{~h}$. The reaction mixture was cooled to room temperature and extracted with ethyl acetate and washed with deionized water and brine solution. Then the combined organic layer was dried over $\mathrm{Na}_{2} \mathrm{SO}_{4}$, and concentrated under vacuum. The crude product was purified by silica-gel column using ethyl acetate/hexane (1:20 by volume) as eluent to afford as a white solid (0.28 g, yield 80\%). MALDI-TOF-MS $(\mathrm{M})(\mathrm{m} / \mathrm{z})=586.41[\mathrm{M}+\mathrm{H}]^{+}$. ${ }^{1} \mathrm{H}$ NMR (600 MHz, $\left.\mathrm{CDCl}_{3}\right): \delta$ 7.79-7.81 (m, 2H), 7.71-7.74 (m, 4H), 1.94-2.01 (m, 4H), 1.39 (s, 24H), 0.99-1.10 (s, 12H). 0.74 (t, $J=8.0 \mathrm{~Hz}, 6 \mathrm{H}), 0.55$ (m, 4H).

\section{Preparation of thin films (take TPA-B as an example)}

\section{Organic phase:}

A solution of TPA-3Br (0.025 mmol, $12 \mathrm{mg}), \mathrm{B}-2 \mathrm{Bpin}(0.036 \mathrm{mmol}, 11.9 \mathrm{mg})$, $\left(\mathrm{t}-\mathrm{Bu}_{3} \mathrm{P}\right)_{2} \mathrm{Pd}(0.01 \mathrm{mmol}, 5.1 \mathrm{mg})$ in xylene $(15 \mathrm{~mL})$

\section{Water phase:}


A solution of $\mathrm{NaOH}(50 \mathrm{mg})$ in pure water $(10 \mathrm{~mL})$

Under an argon atmosphere at room temperature, $10 \mathrm{~mL}$ solution of $\mathrm{NaOH}$ was added slowly into the reaction tube. The $\mathrm{NaOH}$ solution was then covered with pure xylene $(5 \mathrm{~mL})$ and a liquid/liquid two-phase system was formed. Then, the $15 \mathrm{~mL}$ organic phase (including TPA-3Br, B-2Bpin, $\left.\left(\mathrm{t}-\mathrm{Bu}_{3} \mathrm{P}\right)_{2} \mathrm{Pd}\right)$ was added slowly into the interface between the aqueous phase and pure xylene. The reaction system was kept undisturbed, and a light yellow film of TPA-B emerged between the interface of the aqueous phase and organic liquids after $24 \mathrm{~h}$. Pure xylene replacing the organic phase by an injector was the same as the aqueous phase replaced by pure water. The film was fished out by an indium tin oxide (ITO) glass. The TPA-B was removed by ITO substrates and washed by water three times, ethyl alcohol three times and xylene three times to clean the monomers and oligomers.

TPA-B1, 2TPA-B1, TPA-TPA, 2TPA-TPA, TPA-Wu, 2TPA-Wu, 2TPA-B, TPA-EDOT and 2TPA-EDOT are similar with the preparation of TPA-B.

a)

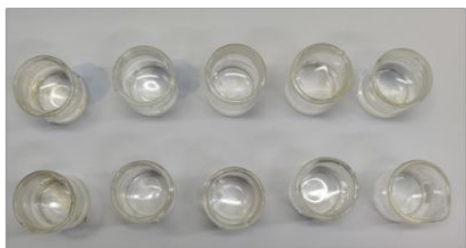

b)
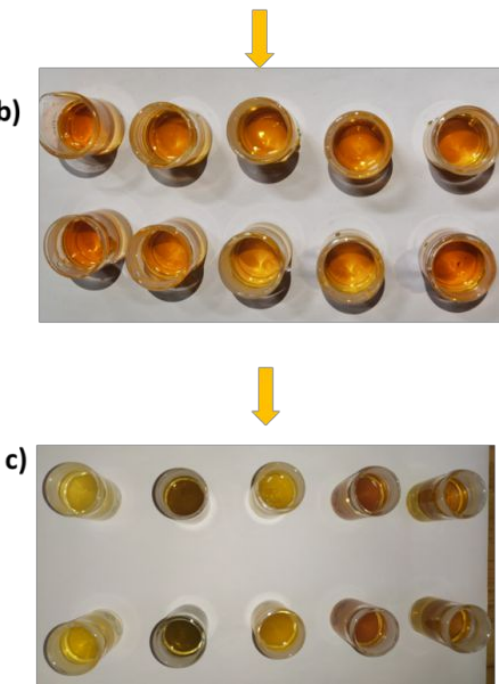

Fig. S1 a) The picture before adding the organic phase b) Digital photograph of the reaction phenomenon at the initial state and c) final state after $24 \mathrm{~h}$. 

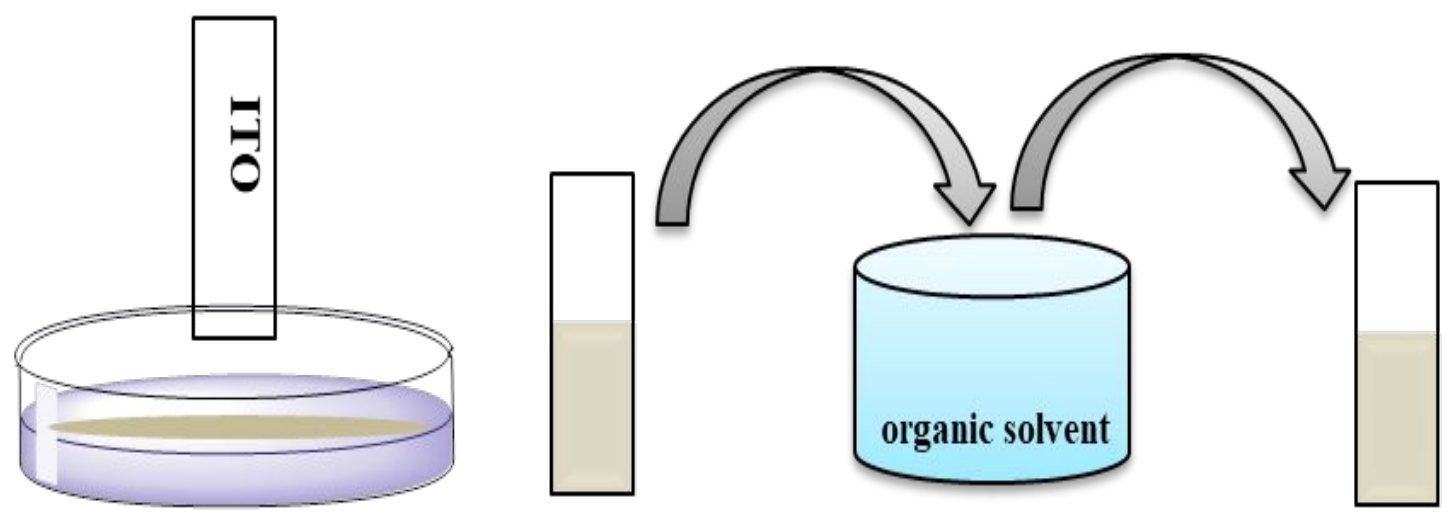

Fig. S2 Transfer procedure for the films to an ITO substrate

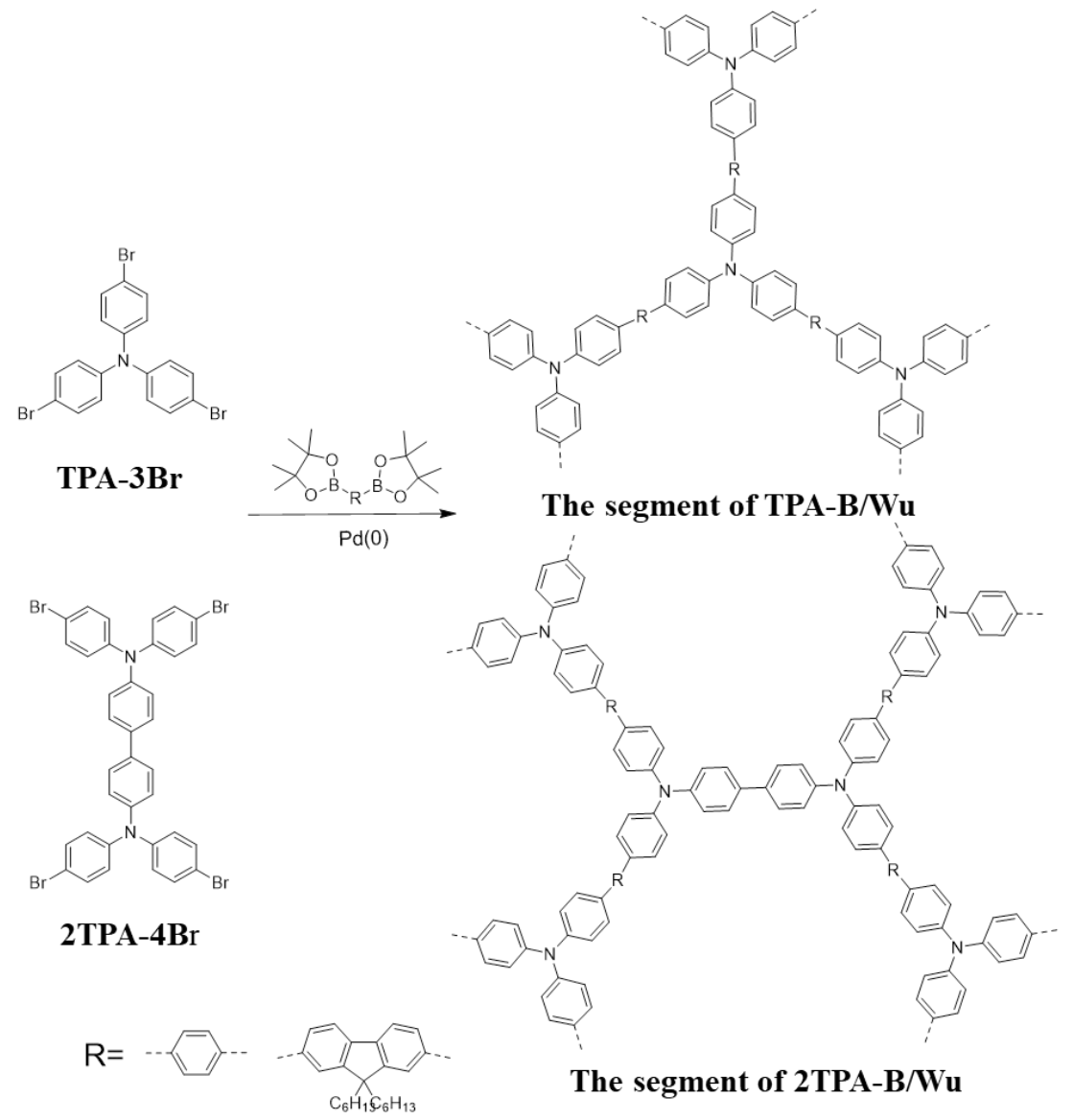

Fig. S3 The possible chemical structure of the TPA-B, TPA-Wu, 2TPA-Wu, 2TPA-B thin film 


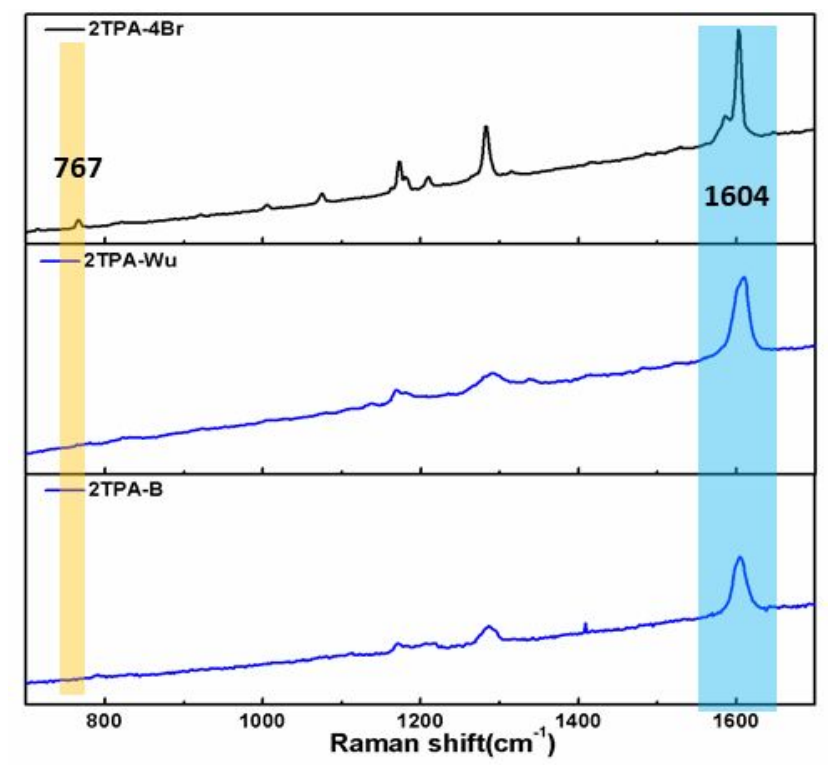

Fig. S4 Raman spectra of 2TPA-4Br precursor and 2TPA-B, 2TPA-Wu on ITO substrates 

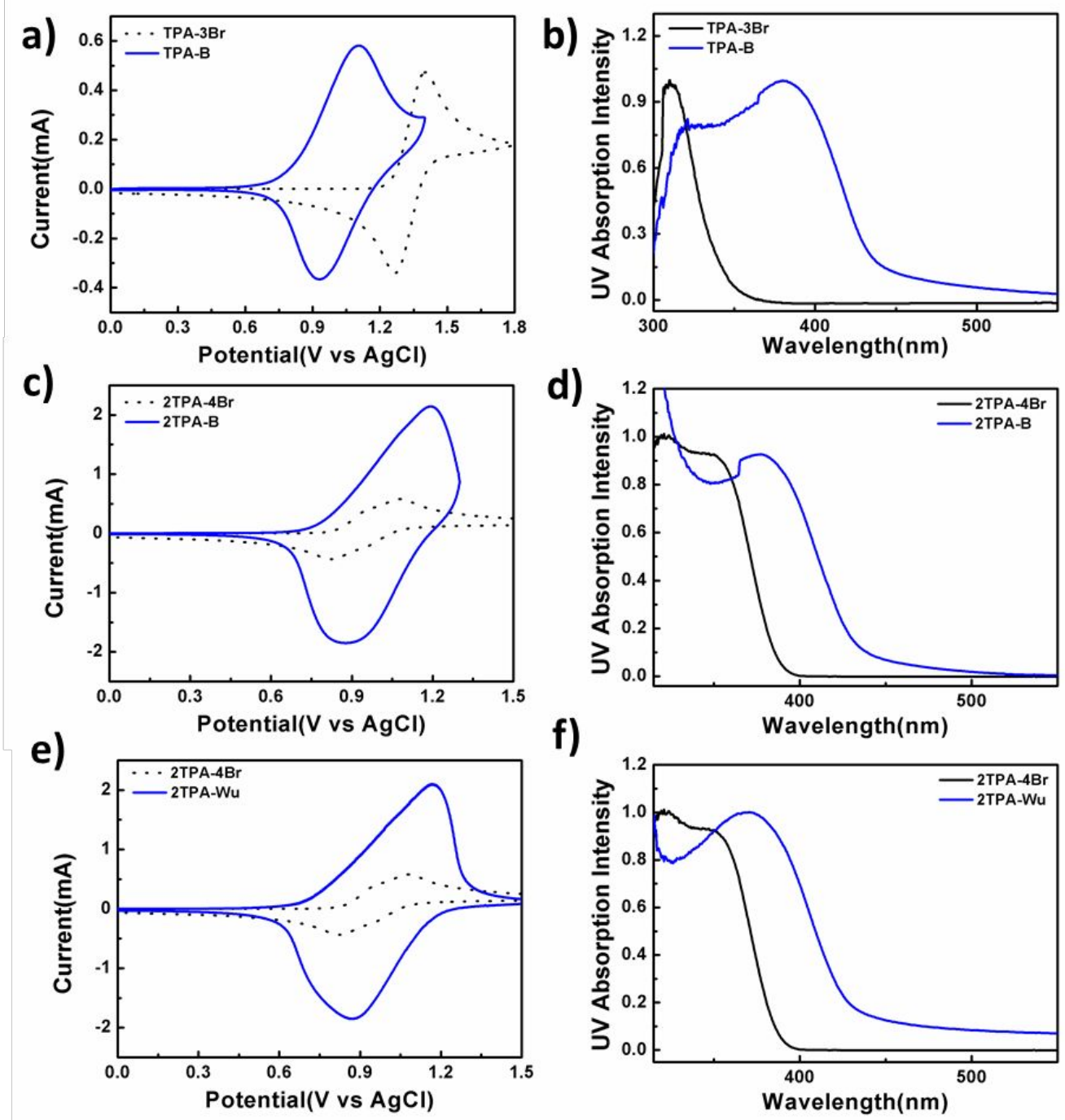

Fig. S5 a) Single scan cyclic voltammetry of TPA-3Br and TPA-B in the solution of ACN containing $0.1 \mathrm{M} \mathrm{TBAPF}_{6}$ at a scan rate of $100 \mathrm{mV} / \mathrm{s}$ b) $\mathrm{UV}$-vis absorbance spectra of TPA-3Br and TPA-B in DCM c) Single scan cyclic voltammetry 2TPA-4Br and 2TPA-B in the solution of ACN containing $0.1 \mathrm{M} \mathrm{TBAPF} 6$ at a scan rate of $100 \mathrm{mV} / \mathrm{s} \mathrm{d}$ ) UV-vis absorbance spectra of 2TPA-4Br and 2TPA-B in DCM e) Single scan cyclic voltammetry of 2 TPA-4Br and 2 TPA-Wu in the solution of ACN containing $0.1 \mathrm{M} \mathrm{TBAPF}$ at a scan rate of $100 \mathrm{mV} / \mathrm{s} \mathrm{f}$ ) UV-vis absorbance spectra of 2TPA-4Br and 2TPA-Wu in DCM 

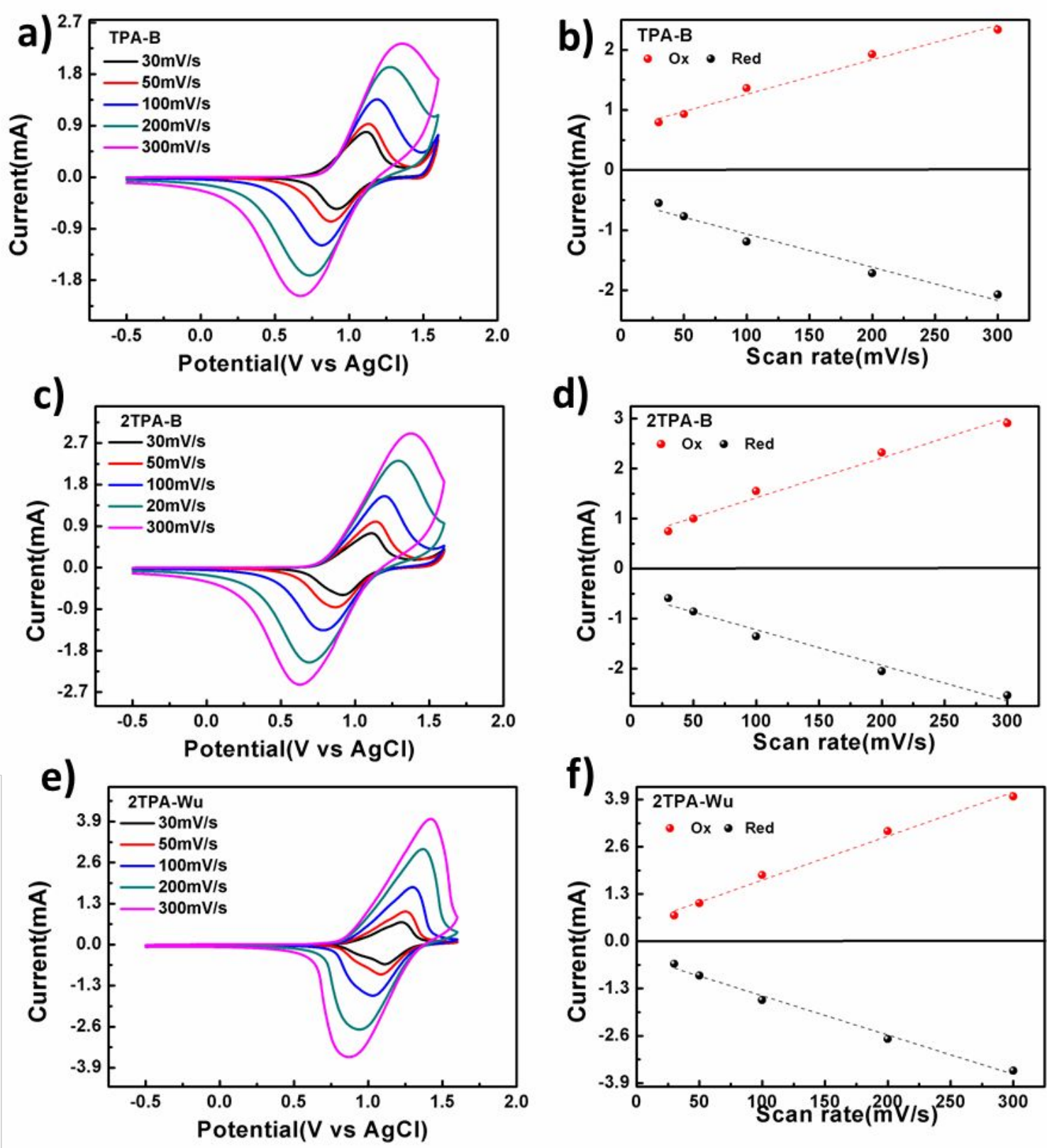

Fig. S6 Cyclic voltammograms of the a) TPA-B, c) 2TPA-B, e) 2TPA-Wu polymer films at different scan rates from $30 \mathrm{mV} / \mathrm{s}$ to $300 \mathrm{mV} / \mathrm{s}$ in in ACN solution containing $0.1 \mathrm{M} \mathrm{TBAPF}_{6}$ and Scan rate vs anodic and the cathodic current density graphs of the b) TPA-B, d) 2TPA-B, f) 2TPA-Wu polymer films 

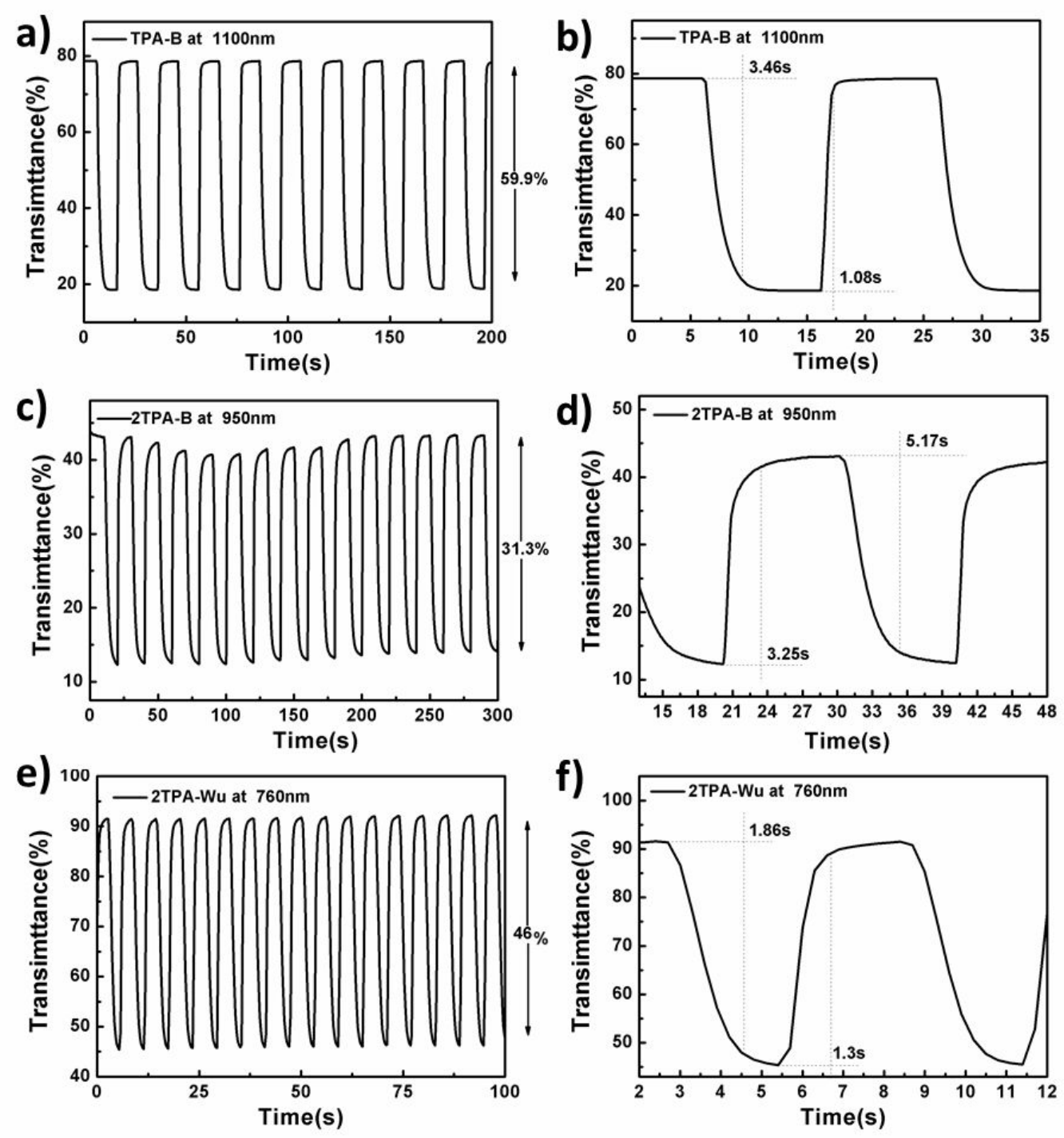

Fig. S7 The optical contrast of a) TPA-B, c) 2TPA-B and e) 2TPA-Wu and switching response of b) TPA-B, d) 2TPA-B and f) 2TPA-Wu in $0.1 \mathrm{M}$ $\mathrm{TBAPF}_{6} / \mathrm{ACN}$. 


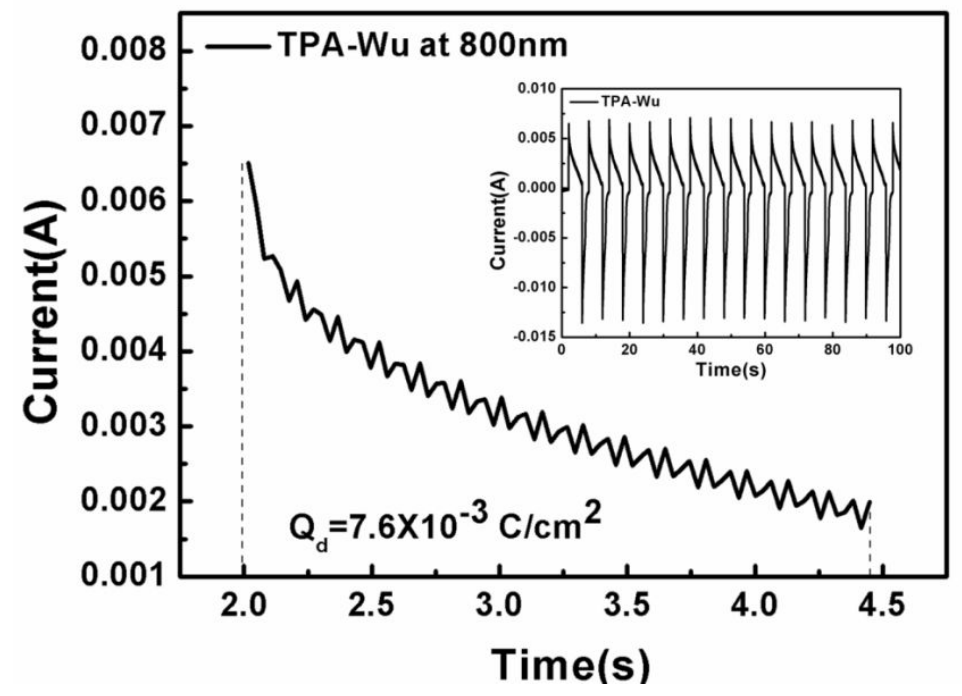

Fig. S8 Chronoamperometry of TPA-Wu with a residence time of $2 \mathrm{~s}$ and $4 \mathrm{~s}$ between $0 \mathrm{~V}$ and $1.3 \mathrm{~V}$ in $0.1 \mathrm{M} \mathrm{TBAPF}_{6} / \mathrm{ACN}$.
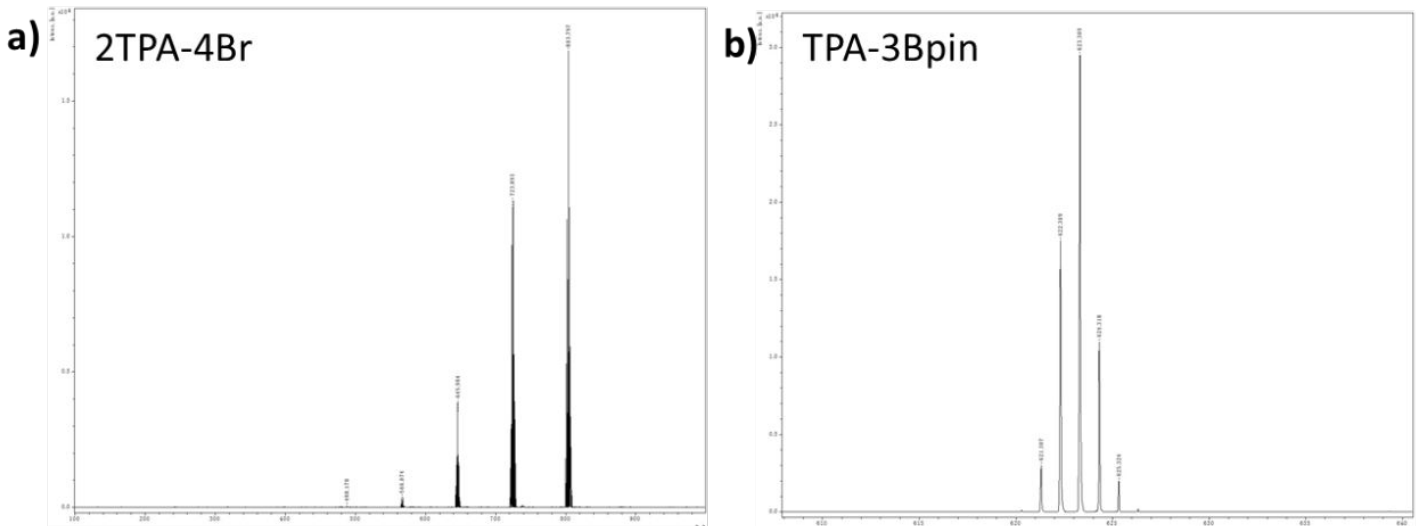

c)

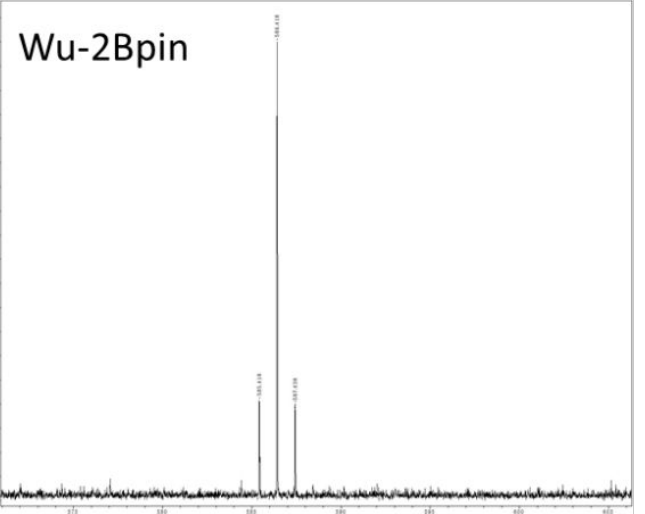

d)

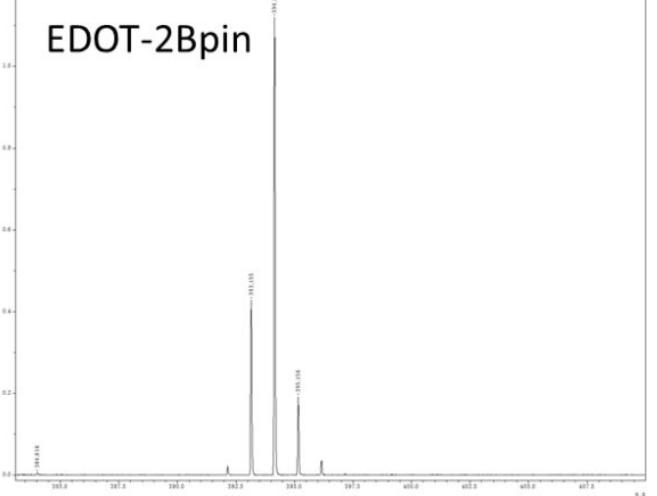

Fig. S9 Mass spectral (MALDI-TOF-MS) analysis of a) 2TPA-4Br, b) TPA-3Br, c) Wu-2Bpin, d) EDOT-2Bpin 